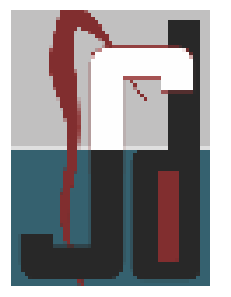

CASE REPORT

\title{
Bridge Flap for the Treatment of Multiple Gingival Recession
}

Gayathri Priyadharshini ${ }^{1}$, Jananni ${ }^{2}$, Saravana Kumar $^{3}$, Pratebha $^{4}$, S.P. Indra Kumar ${ }^{5}$

\begin{abstract}
Gingival recession is defined as the exposure of the root surface by an apical shift in the position of gingiva. Various mucogingival problems such as shallow vestibule, aberrant frenal attachment and inadequate width of attached gingiva if present along with multiple gingival recession becomes additional challenge to cover the denuded root surface. In such situation several surgical technique are needed for the coverage of denuded root surface. Bridge flap technique can be done as a single step entity for all the above mentioned mucogingival problem and it can be treated for multiple gingival recession. This article reports the surgical management of a patient with multiple gingival recession using bridge flap for coverage of denuded root surfaces.
\end{abstract}

Key words : Bridge flap, root coverage, multiple gingival recession

\section{INTRODUCTION}

Gingival recession is defined as the exposure of the root surface by an apical shift in the position of gingiva. The two main etiological factors responsible for gingival recession are periodontitis and faulty tooth brushing habits while other predisposing factors includes high frenal attachment, tooth malposition, thin gingival biotype, bone dehiscence and faulty restorations. ${ }^{1}$ Gingival recession if left untreated results in dentinal hypersensitivity, unesthetic appearance and formation of root caries. Therefore root coverage procedures have become an integral part of regenerative periodontal therapy. ${ }^{2}$ Several classifications of denuded roots have been proposed. Sullivan and Atkins in 1960 classified gingival recession into four morphologic categories and the main disadvantage of this classification is inability to predict the outcome of therapy. Later, Miller in 1985 proposed classification system for gingival recession and complete coverage can be expected only with class 1 and class 2 type of gingival recession. ${ }^{3}$ Surgical root coverage may be achieved by a number of technique. Various mucogingival problems such as shallow vestibule, aberrant frenal attachment and inadequate width of attached gingiva if present along with multiple gingival recession becomes additional challenge to cover the denuded root surface. In such situation several surgical technique are needed for the coverage of denuded root surface. Bridge flap technique can be done as a single step entity for all the above mentioned mucogingival problem and it can be treated for multiple gingival recession. Marggraf proposed bridge flap technique in $1985 .{ }^{4}$ The advantage of this technique are that it does not required a second surgical site and it does not require separate frenectomy procedure. ${ }^{4}$ This article presents a case reportof a patienttreated using Bridge flap technique.

\section{CASE REPORT}

A 23 year old female patient reported with a chief complaint of tooth sensitivity and receding gums in her lower front teeth region. The patient had no relevant medical history and was not taking any medication. The patient presented with Millers class II gingival recessionof $4 \mathrm{~mm}$ in relation to 31,41 and 42 (figure 1). The width of attached gingiva was $2 \mathrm{~mm}$ on 31,41 and 42. Probing pocket depth of $2 \mathrm{~mm}$ was present on teeth 31,41 and 42. Bridge flap technique was planned for root coverage in relation to 31,41 and 42 . The surgical technique was explained to the patient and informed consent was obtained. Scaling and root planning was performed. The patient was then recalled after two weeks for surgery.

\section{Surgical technique}

Bridge flap technique included an arc shaped incision in the vestibule. An incision into the periosteum was placed at its base and the bone was exposed so that scar formation can occur. 


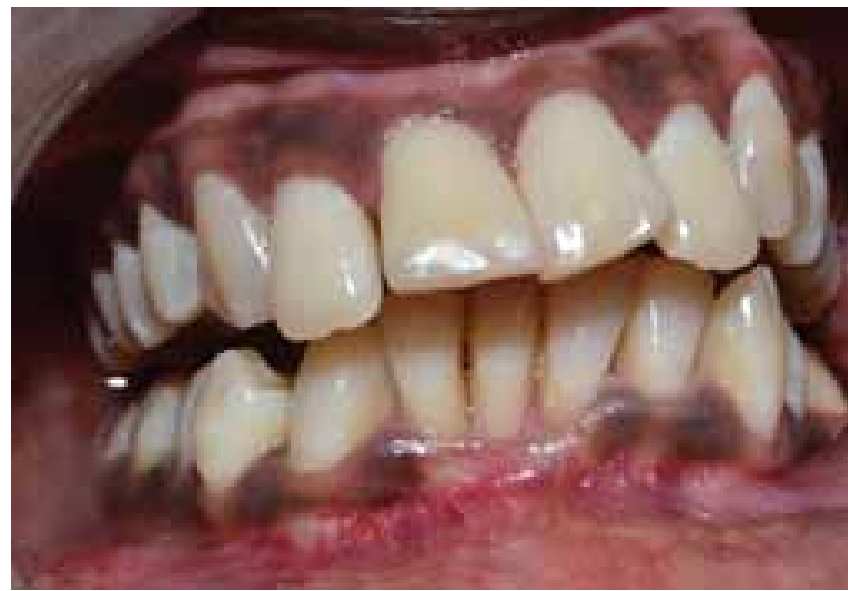

Figure 1: Pre Operative

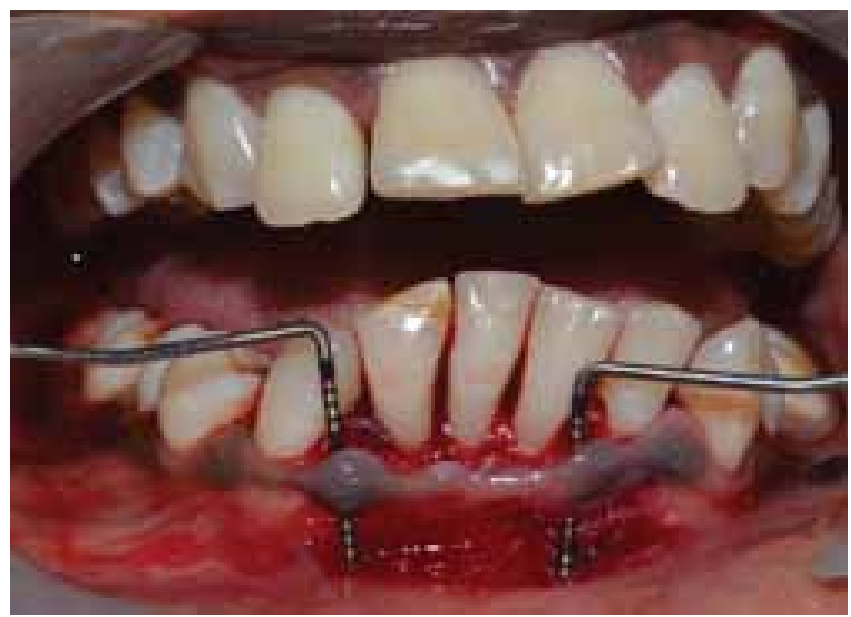

Figure 3: Bridge flap elevated

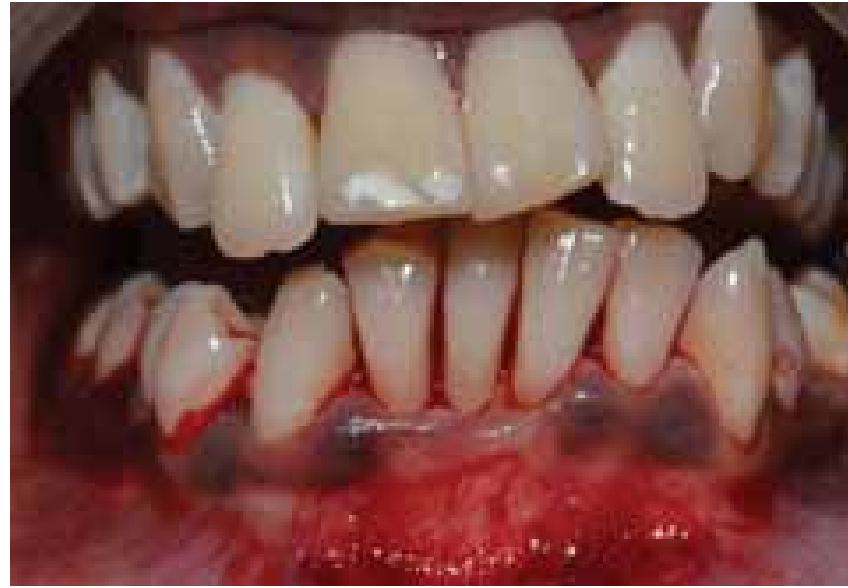

Figure 2: Intra-Operative photograph of Arc-Shaped Incision.

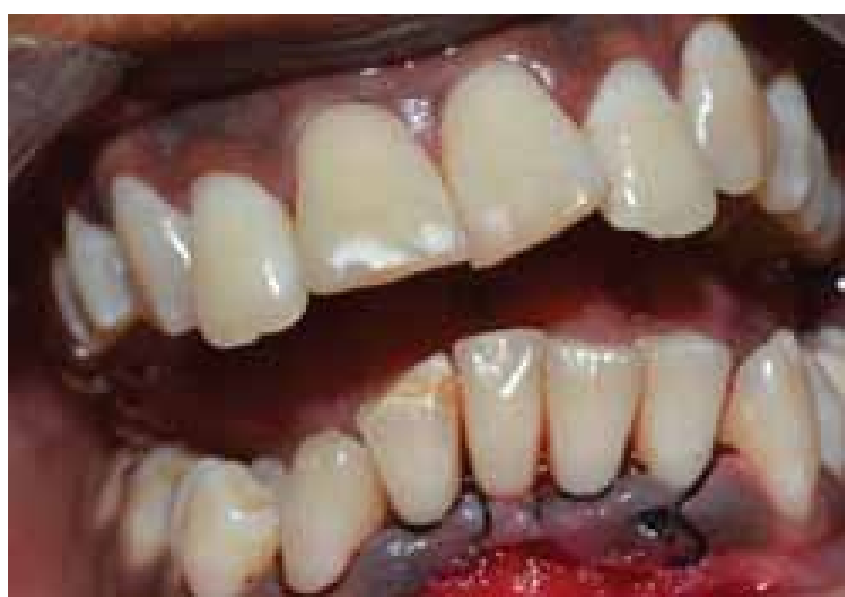

Figure 4: Bridge flap coronally positioned and Sutured

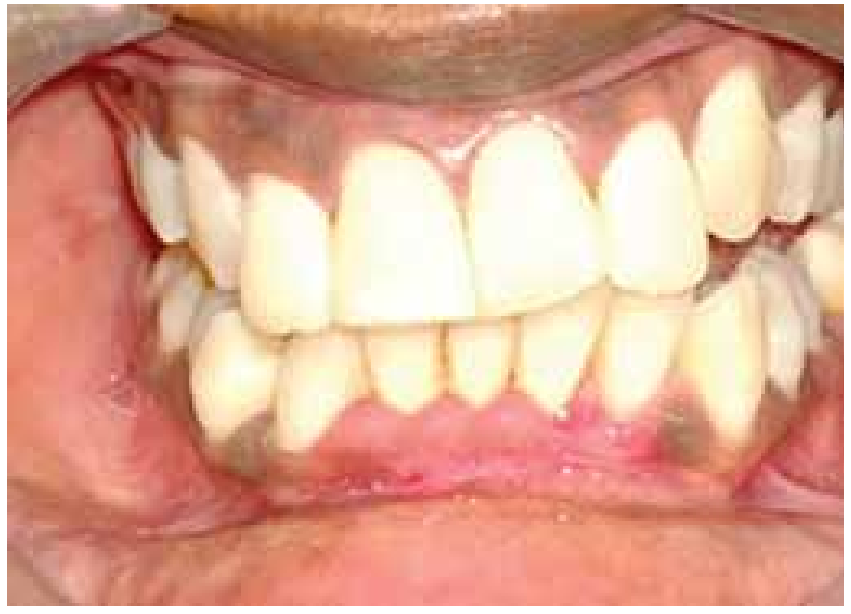

Figure 5: Post Operative -3 months. 
A split thickness flap was elevated in apicocoronal direction by making a sulcular incision, connecting it with the first incision so that the whole bridge flap could be elevated and repositioned coronally to cover the denuded root surface. The repositioned flap was then pressed for three minutes and independent sling sutures were placed. Coepack were placed covering the surgical area. ${ }^{5}$

\section{Post operative care}

Post operative instructions were given to the patient. Amoxicillin 500mg trice daily was for 5 days and combiflam twice daily for 3 days were prescribed. Patient was instructed to rinse with chlorhexidine solution trice daily for 4 weeks. Patient was recalled after two weeks for suture removal. Healing was satisfactory. Complete root coverage obtained in 3 months post operative follow up (figure 5).

\section{DISCUSSION}

The intention of root coverage is complete restoration of all anatomical structures in the area of recession. Clinically the aim of root coverage according to Miller and Harris are coverage of recession up to mucogingival junction, probing depth less than $2 \mathrm{~mm}$, no bleeding on probing, wide keratinized gingiva, smallest possible color difference from the adjacent gingiva, physiologic shape and surface of gingiva. ${ }^{6,7}$ Numerous surgical techniques have been proposed to treat gingival recession. One such technique is bridge flap technique proposed by marggraf. ${ }^{4}$ It is a single step solution to eliminate the problem of gingival recession and hypersensitivity even in the presence of shallow vestibule and high frenal pull. In the above case there was complete root coverage obtained as defined by Miller et al (1985). ${ }^{3}$ The result of the case report in obtaining complete root coverage are consistent with the studies done by Gupta et $\mathrm{al}^{8}$, Marggraf et $\mathrm{al}^{4}$ and Musalaiah et al. ${ }^{9}$ However gain in width of attached gingiva is minimal in the above case which is similar to the studies done by Marggraf et al, ${ }^{4} \mathrm{Vijayalaxmi}$ et al ${ }^{10}$ and Romanos et $\mathrm{al}^{5}$ whereas in a study done by Gupta et $\mathrm{al}^{8}$ there was average gain of $3.5 \mathrm{~mm}$ of attached gingiva.

\section{CONCLUSION}

A wide variety of periodontal plastic procedures have been described to correct mucogingival problems and to cover denuded root surfaces. In the above treated case, bridge flap technique was successful in treating multiple teeth gingival recession in the presence of shallow vestibule in a single step

\section{REFERENCES}

1. Loe H, Anerud A, Boysen H. The natural history of periodontal disease in man: prevalence, severity, and extent of gingival recession. J Periodontol 1992;63:489-95.

2. Baker D, Seymour G. The possible pathogenesis of gingival recession. J ClinPeriodontol 1976;3:208-19.

3. Miller PD. A classification of marginal tissue recession. Int $\mathbf{J}$ Periodontics Restorative Dent 1985;5:8-14.

4. Marggraf E. A direct technique with a double lateral bridging flap for coverage of denuded root surface and gingival extension. Clinical evaluation after 2 years. J ClinPeriodontol 1985;12:69-76.

5. Romanos GE, Bernimoulin JP, Marggraf E. The double lateral bridging flap for coverage of denuded root surface. Longitudinal study and clinical evaluation after 5 to 8 years. J Periodontol 1993;64:683-88.

6. Erpenstein and Borchard. Criteria for the selection of root coverage procedures: part 1. Perio 2006;3(2):139-152.

7. Sato N. Periodontal surgery: A clinical atlas: Increasing the attached gingiva. London: Quintessence Publishing Co. Ltd, 2008:82-125

8. Gupta V, Bains VK, et al. Bridge flap technique as a single step solution to mucogingival problems: A case series. Contemporary Clin Dent 2011; 2: 110-14.

9. Musalaiah S, Krishna VS, Kumar PA, Nagasree M. Double lateral sliding bridge flap for the treatment of multiple gingival recessions: case series. Journal of Orofacial Research 2012;2(4):247-50.

10. Vijayalakshmi R, Uma S, SaravanaKumar R, Ramakrishnan T, Emmadi P, Anitha V. The double lateral bridging flap for coverage of denuded root surface: Two case reports. PERIOPeriodontPract Today 2008;5:29-33. 


\section{Address of Correspondence}

Dr. Gayathri PriyadharshinI MDS,

Senior Lecturer,

Department of Periodontology,

Indira Gandhi Institute Of Dental Sciences,

Puducherry.

Email id : gayathriaelangovan@gmail.com

Phone no : 9944150599

\section{Authors:}

${ }^{1}$ Senior Lecturer, Department of Periodontology, Indira Gandhi Institute Of Dental Sciences, Puducherry.

${ }^{2}$ Senior Lecturer, Department of Periodontology, Indira Gandhi Institute of Dental Sciences, Puducherry.

${ }^{3}$ Prof and Head, Department of Periodontology, Indira Gandhi Institute Of Dental Sciences, Puducherry.

${ }^{4}$ Professor, Department of Periodontology, Indira Gandhi Institute of Dental Sciences, Puducherry, India.

${ }^{5}$ Assistant Professor, Department of Dentistry, Aarupadai Veedu Medical College \& Hospital, Puducherry.

\section{How to cite this article :}

Gayathri Priyadharshini, Jananni, Saravana Kumar, Pratebha, S.P. Indra Kumar. Bridge Flap for the Treatment of Multiple Gingival Recession. Journal of Scientific Dentistry, 2016;6(1):30-33

Source of Support : Nil, Conflicts of Interest : None declared 